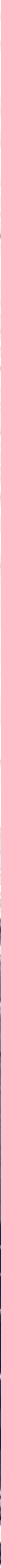

$\therefore$

s.

$\frac{1}{4}+4$

$+x^{2} x^{\circ}$

8

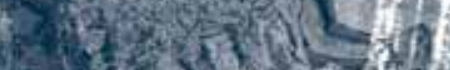

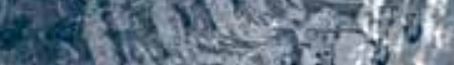




\title{
El gran rechazo digital en La Primavera Mexicana
}

\author{
The great digital repudy in Mexican Spring
}

Dor: 10.15213/redes.n10.p75

OCTAVIO ISLAS

\begin{abstract}
In the first section of this text, I highlight the important role that social networks have been observed in recent expressions of protest and liberation movements in some Arab countries, the M-15 movement in Spain, the "protesters" in the UK, and the movement Occupy Wall Street, in the U.S., and recovery core concept that Herbert Marcuse proposed in the 1960 s to designate the student movement: "the great refusal". Then I focus on Mexico, referring to some of the main background of the presidential election held on the first Sunday of July 2012. I note how Televisa observed a leading role in the presidential campaign of Enrique Peña Nieto, who was extensively questioned by students at the Universidad Iberoamericana (UIA), when in a campaign visited the said university. The awkward disqualification of students objected to the presence of Peña Nieto at the campus gestation led \#YoSoy132, aesthetic movement that effectively said hope - as the ability - to take the deep and essential reconstruction of Mexico.
\end{abstract}

KEYWORDS: \#YOSOY132, SOCIAL NETWORKS, AESTHETIC MOVEMENT

\section{RESUMEN}

En el primer apartado de este texto destaco el relevante papel que han observado las redes sociales en recientes expresiones de protesta y movimientos de liberación en algunos países árabes, el movimiento M-15 en España, los “inconformes" en Reino Unido, y el movimiento Occupy Wall Street, en Estados Unidos, y recupero un concepto medular que Herbert Marcuse propuso en la década de 1960 para designar los movimientos estudiantiles: "el gran rechazo". Enseguida centro mi atención en México, refiriendo algunos de los principales antecedentes de los comicios presidenciales celebrados el primer domingo de julio de 2012. Señalo cómo Televisa observó un rol protagónico en la campaña presidencial de Enrique Peña Nieto, quien fue objeto de amplios 
cuestionamientos por parte de estudiantes de la Universidad Iberoamericana (UIA), cuando en un acto de campaña visitó la referida universidad. La torpe descalificación de los estudiantes que objetaron la presencia de Peña Nieto en ese recinto universitario propició la gestación de \#YoSoy132, movimiento estético que efectivamente afirmó la esperanza - como la posibilidad - de emprender la profunda e indispensable reconstrucción de México.

PALABRAS CLAVE: \#YOSOY132, REDES SOCIALES, MOVIMIENTO ESTÉTICO

\section{EL GRAN RECHAZO DIGITAL}

"Sigue, pues, siendo verdad que el capitalismo crece a costa de un empobrecimiento creciente y que éste será un factor básico de la revolución, aunque adopte formas históricas nuevas". - Herbert Marcuse.

En años recientes las redes sociales han observado un relevante papel en expresiones de inconformidad y protesta social, así como en movimientos de liberación ciudadana. En 2009, durante la llamada "Revolución Iraní", Internet fue considerado como un "medio libertador". Tras los comicios presidenciales celebrados el 12 de junio de ese año, de los cuales se desprendió la cuestionada reelección de Mahmoud Ahmadinejad ${ }^{1}$, grupos de ciudadanos inconformes emplearon Internet y particularmente las redes sociales para organizar las expresiones de protesta y rechazo a los resultados que arrojaron esos comicios. Naturalmente la movilización de la sociedad iraní generó gran interés en la prensa internacional. No sin cierta exageración el diario The New York Times afirmó que los manifestantes "disparaban tweets" frente a las balas ${ }^{2}$. Por supuesto algunos analistas afirmaron que la mitificación libertaria de las redes sociales en la revuelta iraní, en realidad respondió a propósitos eminentemente mercadológicos de Twitter y Facebook. Sin embargo, la rebelión en Irán antecedió a un conjunto más amplio de movimientos de liberación nacional - la llamada "Primavera Árabe" -, la

1. Ahmadinejad, quien llegó al poder en 2005, según los datos oficiales obtuvo 62.63 por ciento de los votos en los comicios celebrados en 2009, y Mir-Hossein Mousavi, principal candidato opositor, recibió 33 por ciento de los sufragios.

2. Véase: http://www.rsf-es.org/grandes-citas/dia-contra-censura-en-internet/a2011-dia-mundialcontra-la-censura-en-internet/frente-a-la-censura-solidaridad-en-la-red/ Fecha de consulta: 28 de septiembre de 2013. 
cual comprendió una serie de levantamientos populares entre 2010 y 2011 en Arabia Saudi, Argelia, Baréin, Egipto, Irán, Irak, Jordania, Kuwait, Líbano, Libia, Marruecos, Mauritania, Omán, Sahara Occidental, Somalia, Siria, Sudán, Túnez, Yemen y Yibuti.

Es posible afirmar que las redes sociales - particularmente Twitter y Facebook - cumplieron útiles funciones de vinculación y enlace entre la ciudadanía inconforme, estimulando, además, la amplia cobertura informativa que la prensa internacional concedió a los movimientos de protesta ciudadana en los mencionados países. De ninguna manera pretendo afirmar que Internet y los nuevos medios sociales detonaron las revueltas, las cuales fueron consecuencia de profundas desigualdades, miseria, autoritarismo, exclusión social y la manipulación informativa que prevalece en esas naciones. Sin embargo, debemos reconocer que la notoriedad mediática que alcanzaron los referidos movimientos de liberación nacional, definitivamente resultaría improbable sin el uso de Internet y las principales redes sociales. En Egipto, Libia, Túnez y Yemen la ciudadanía inclusive consiguió deponer a sus respectivos jefes de Estado, quienes habían conservado el poder durante décadas.

Un aspecto muy interesante a destacar en la llamada "Primavera Árabe" fue la singular batalla informativa que libraron los nuevos medios sociales frente al conjunto de medios masivos convencionales. Los medios de comunicación convencionales apostaron por la contrarrevolución. La ciudadanía, a través de los nuevos medios sociales, por la revuelta. Cómplices del poder, los medios masivos convencionales se desempeñaron como firmes aliados de los jefes de los gobiernos autoritarios y represores. Sin embargo, éstos no fueron capaces de poder contener el flujo informativo que circuló a través de los nuevos medios sociales. Frente al discurso unilateral autoritario, decretado desde el poder para ser reproducido literalmente por los medios convencionales, la ciudadanía se apropió de las redes sociales, y a través de éstas dio a conocer contundentes críticas a sus gobernantes. Los movimientos de liberación nacional sencillamente afirmaron las posibilidades de las "tecnologías liberadoras”, destacando, particularmente, las redes sociales.

El empleo ubversivo de las redes sociales durante la llamada "Primavera Árabe" de ninguna manera representa un hecho aislado. También fueron empleados Internet y las principales redes sociales como plataformas de organización y efectivos medios propagandísticos en el Movimiento 15-M en España, con los inconformes en el Reino Unido y en el movimiento Occupy Wall Street en Estados Unidos. Los argumentos del nuevo gran rechazo digital son tan razonables como contundentes. No pocos gobiernos han sido cómplices de bancos y poderosas corporaciones que hacen muy poco para 
remediar la profunda desigualdad que prevalece. En el mundo hay millones de personas sin empleo. En cambio la riqueza se concentra en un muy reducido número de personas, como Bill Gates y Carlos Slim. En buena medida Internet, y particularmente las redes sociales, han permitido dar a conocer las legítimas razones de la profunda inconformidad de millones de personas en el mundo:

"hoy las 250 personas más ricas del mundo tienen ingresos equiparables a los de un tercio de la humanidad. Tres familias tienen un ingreso similar al de los 940 millones de personas más pobres del planeta (...) más de 1,00o millones de personas no tienen empleo o están por abajo de la línea de dignidad e sus tareas diarias (...) sólo el $8 \%$ vive en el mundo en condiciones de seguridad para crear y crecer”. (Duró 2005, pág. 95).

En nuestros días extraños advertimos condiciones históricas propicias para el desarrollo del gran rechazo digital. Internet representa una notable diferencia cualitativa sobre los movimientos estudiantiles registrados durante la agonía de la década de 1960. El "medio de comunicación inteligente" es fertil territorio abierto a las utopías y está al servicio de los ciudadanos.

"Las posibilidades utópicas se hallan implícitas en las fuerzas técnicas y tecnológicas del capitalismo y el socialismo avanzados: la utilización racional de estas fuerzas en una escala global acabaría con la pobreza y la escasez en un futuro muy previsible" (Marcuse 1969, p.11)

\section{LA PRIMAVERA MEXICANA}

\subsection{ANTECEDENTES}

Hasta el primer cuatrimestre de 2012, en México habíamos permanecido relativamente indiferentes y ajenos a las razones universales de la indignación y protesta expresadas en otras naciones a través de las redes sociales. En los comicios presidenciales celebrados en 2006, a Felipe Calderón, candidato del Partido Acción Nacional (PAN), partido político de la derecha, la cual llegó al poder en el año 2000 con Vicente Fox Quezada, fueron reconocidos 15,000,284 votos legales (35.89 por ciento); Andrés Manuel López Obrador, candidato de la Coalición Por el Bien de Todos, integrada por el 
Partido de la Revolución Democrática (PRD), el Partido del Trabajo (PT) y Convergencia - hoy Movimiento Ciudadano (MC) - , fueron reconocidos 14,756,350 sufragios (35.33 por ciento). Roberto Madrazo Pintado, candidato del Partido Revolucionario Institucional (PRI), partido que gobernó México desde 1929 como Partido Nacional Revolucionario (PNR), recibió 9,301,441 votos (22.26\%). La diferencia en el número de votos legales emitidos a favor de Felipe Calderón y Andrés Manuel López Obrador - candidato de la izquierda - fueron 243,934 sufragios ( 0.5 por ciento). En tan cerradas elecciones es posible afirmar que lo que se hizo en Internet, y también, por supuesto, lo que dejó de hacerse, resultó determinante en el resultado de los comicios.

En las llamadas elecciones intermedias, celebradas en julio de 2009, en las cuales fue renovada la Cámara de Diputados, Twitter observó un papel incipiente. Apenas un reducido número de candidatos a puestos de elección ciudadana tenían cuentas en Twitter, y básicamente empleaban Facebook para dar a conocer la agenda de sus actividades en campaña a sus pocos seguidores en la mencionada red social. En esas elecciones irrumpieron en Facebok algunos movimientos que pretendieron - sin éxito - persuadir a la ciudadanía de la necesidad de anular sus votos. En esos movimientos participaro activamente algunos miembros y simpatizantes del Partido Acción Nacional. A pesar de los negativos resultados que el pan obtuvo en las elecciones intermedias - dirigido de facto por Felipe Calderón, el presidente de la República -, el partido de la derecha no fue capaz de poder corregir el rumbo. Con gran anticipación a la celebración de los comicios presidenciales del primer domingo de julio de 2012, la mayoría de los especialistas pronosticaba que el PAN perdería el poder, como efectivamente ocurrió.

En los comicios para elegir al nuevo gobernador del Estado de México - 3 de julio de 2011 -, el equipo de campaña de Eruviel Ávila, candidato del Partido Revolucionario Institucional (PRI), del Partido Verde Ecologista de México (PVEM), y el Partido Nueva Alianza (PANAL), desplegó una intensa ofensiva a través de redes sociales, la cual incluyó la primera adquisición masiva de bots en México. Esa operación efectivamente permitió incrementar el número de seguidores de Eruviel Ávila en las redes sociales. Las elecciones en el Estado de México - la entidad más poblada del país y que cuenta con el mayor número de electores registrados en el padrón electoral -, por celebrarse un año antes de los comicios presidenciales, son consideradas como el lógico escenario de experimentación propagandística, en la perspectiva de las elecciones presidenciales que celebraríamos un año después, en julio de 2012. 
En el desarrollo de su campaña en el Estado de México, el PRI anticipó algunas de las acciones que implementaría a través de Internet y en las redes sociales durante la campañas presidencial en 2012. Alejandra Lagunes Soto Ruiz, egresada de la licenciatura en ciencias de la comunicación en el Tecnológico de Monterrey, campus Estado de México, se desempeñó como principal responsable de las acciones emprendidas a través de redes sociales en la campaña de Eruviel Ávila. El equipo de campaña de Eruviel Ávila en Internet operó para conseguir que en algunos de los principales buscadores en la red, los nombres de los candidatos opositores - Luis Felipe Bravo Mena (PAN), y Alejandro Encinas Rodríguez (PRD) - remitieran a las páginas web de Eruviel Ávila.

La única esperanza de poder impedir el retorno del PRI al poder dependía de la eventual derrota de Eruviel Ávila en los comicios en el Estado de México. Sin embargo, no fue así, los candidatos del PAN y PRD (Bravo Mena y Encinas) fueron vapuleados. En las elecciones en el Estado de México, el PRI no escatimó recursos lícitos e ilícitos para garantizar el triunfo de Eruviel Ávila. Del mismo modo procedería el PRI en las campañas presidenciales en 2012, en las cuales tampoco escatimó recursos lícitos e ilícitos para garantizar el triunfo de Enrique Peña Nieto, y el consecuente arribo al poder del llamado "Grupo Atlacomulco" - poderoso grupo de industriales, empresarios y principalmente políticos, dueños indiscutibles del poder en el Estado de México -

Mucho antes de que el PRI designará a Enrique Peña Nieto como su candidato presidencial, amplios sectores de la sociedad advertieron el privilegiado tratamiento informativo que Televisa venía concediendo a Peña Nieto, gobernador del Estado de México durante el periodo 2005-2011. La citada televisora observó un rol protagónico en el confeccionamiento de la candidatura presidencial de Enrique Peña Nieto, desde el inicio mismo del gobierno del presidente Felipe Calderón (2006). De acuerdo con el destacado periodista Jenaro Villamil: "El sexenio de Televisa inició antes de las elecciones presidenciales del 2 de julio de 2006 y pretende prolongarse más allá del 2012" (Villamil. 2010, pág. 13). Alejandro Quintero, uno de los principales directivos de Televisa, desde 2003 "tomó el control de los contenidos de Televisa para subordinarlos a la estrategia de comercialización" de la televisora (Villamil 2012, pág.23). Televisa comercializaría, como cualquier producto, la imagen del político mexiquense. Para ello creó una serie de empresas encargadas de promover la imagen del entonces gobernador del Estado de México (TVPromo, Radar Servicios Especializados y Mediamates Group). En una de esas empresas precisamente laboraba Alejandra Lagunes. La imagen pública 
de Enrique Peña Nieto estaba en manos de Televisa. Inclusive los spots promocionales del Quinto Informe de Gobierno de Peña Nieto, en el Teatro Morelos, estuvieron a cargo de Pedro Torres, el principal productor de Televisa"3. Las investigaciones periodísticas realizadas por Jenaro Villamil Si yo fuera presidente. El reality show de Peña Nieto (2009) y, El sexenio de Televisa. Conjuras del poder mediático en México (2010), han permitido demostrar la interesada participación de Televisa ${ }^{4}$ en la costosa promoción de Enrique Peña Nieto. En 2009, Jenaro Villamil afirmó:

\begin{abstract}
"Peña Nieto se ha convertido en una gran inversión y no en un proyecto político genuino. Es el producto más vulnerable y maleable de cuantos han existido en el Grupo Atlacomulco. No es el primer gobernante de la entidad más poblada del país que ha aspirado ser presidente. Antes que él, Carlos Hank González,
\end{abstract}

3. A partir del año 2000 Televisa y TV Azteca decidieron participar de forma más directa en la política nacional, y ya no depender exclusivamente del cabildeo a modo que han venido realizando a su favor determinados brokers de la política nacional, como Emilio Gamboa Patrón, líder de la Confederación Nacional Obrera Popular (CNOP), una de las columnas vertebrales del voto corporativo priista. A partir del año 2000, ex empleados de las televisoras, como Jorge Mendoza Garza — quien se desempeñó como vicepresidente de Información y Asuntos Públicos en Televisión Azteca, y posteriormente como presidente de la Cámara Nacional de la Industria de Radio y Televisión (CIRT) - , y por supuesto, algunos políticos que han cultivado una estrecha relación con las televisoras, lograron ser postulados por los partidos políticos - principalmente PRI y PVEM - para ir ocupando cada tres años un mayor número de curules en la Cámara de Diputados, conformando así la llamada "telebancada”, cuya función principal radica en defender los intereses de Televisa y tv Azteca. Las televisoras ni siquiera se han preocupado por simular la subordinación de la telebancada a sus intereses muy particulares. Ninfa Salinas, hija de Ricardo Salinas - dueño de Tv Azteca, quien concede mayor importancia a las transmisiones de los partidos de fútbol que a los debates entre los candidatos presidenciales - en la Lxi legislatura se desempeñó como diputada federal del PVEM. En la LXII Legislatura llegó al Senado de la República por el principio de representación proporcional.

4. A mediados de la década de 1980 , la credibilidad informativa de Televisa fue sumamente cuestionada. El noticiero 24 Horas, a cargo del periodista Jacobo Zabludovsky, inclusive fue objeto de un boicot publicitario, el cual fue promovido por Manuel de Jesús Clouthier, candidato del PAN a la presidencia de la República en 1988. Emilio Azcárraga Milmo — padre de Emilio Azcárraga Jean, dueño de Televisa, y quien por esas fechas se declaró “soldado del PRI" (Fernández y Paxman, 2000) —, así definía la política informativa de Televisa: "Nosotros somos del PRI, siempre hemos sido del PRI; no creemos en ninguna otra fórmula. Y como miembros de nuestro partido haremos todo lo posible porque nuestro candidato triunfe" (Fernández y Paxman 2000, pág. 320).

REDES.COM N $\mathrm{N}^{\circ} 10 \mid 81$ 


\begin{abstract}
Alfredo del Mazo González, Emilio Chuayffet y Arturo Montiel acariciaron esa ambición. Y no lo lograron. Se movieron bajo las reglas antiguas de la institucionalidad priista y, al cumplirlas, sólo se quedaron con sus pretensiones frustradas. A cambio, se enriquecieron ellos y sus principales colaboradores (...) Lo singular en el caso de Peña Nieto es la sustitución de aquellas viejas reglas del PRI por unas nuevas dependientes del poder mediático: la suplantación de la política por la mercadotecnia, la construcción de un liderazgo aparente cuyo afianzamiento depende más del rating que de la eficacia y la credibilidad. Le ha apostado todo a la inversión publicitaria, a la compra intensiva de tiempo y apoyo en la televisión mexicana, especialmente en Televisa. Es el resultado de una realidad virtual". (Villamil 2009, págs. 15-16).
\end{abstract}

Enrique Peña Nieto no solo representaba una atractiva inversión para Televisa, su candidatura presidencial también era un lucrativo negocio para distinguidos miembros del viejo PRI, quienes aspiraban retornar al poder a través de Peña Nieto:
"El ex presidente Carlos Salinas, desde la nostalgia por sus años gloriosos, asesora a Peña Nieto, lo apoya y lo recomienda; es uno de sus principales negocios. Del mismo modo, brokers políticos de la talla de Emilio Gamboa Patrón, líder de los diputados priistas, ya juegan sus fichas por el Golden boy en el casino de 2012". (Villamil 2009, pág. 23).

Si Televisa observó un papel protagónico en el diseño de la candidatura presidencial de Enrique Peña Nieto, algunas firmas dedicadas a la investigación del mercado electoral realizaron una significativa contribución a la campaña presidencial del mexiquense. Los resultados de los estudios realizados por determinadas casas encuestadoras - destacando algunas de las firmas que trabajan para Grupo Televisa, como Consulta Mitofsky y Grupo Milenio (GEA-ISA) - , permitieron persuadir a amplios sectores de la ciudadanía de la ventaja definitiva que había logrado establecer Enrique Peña Nieto sobre los otros candidatos presidenciales (Josefina Vázquez Mota, por el pan y Andrés Manuel López Obrador, por una coalición de partidos políticos de izquierda). Sin embargo, el porcentaje de indecisos y posibles switchers era aún considerable, como afirman Galindo y González: "El 30 de marzo, al inicio de la 
campaña, 60\% de los electores eran switchers (no habían definido su voto). El 1 de julio, día de las elecciones, el 40\% seguían siendo switchers". (Galindo y González 2002, pág. 23). El destacado periodista Jenaro Villamil agudamente señala que la tarea asignada a determinadas casas encuestadoras fue realizar spots inductivos. Los resultados que ofrecieron a la opinión pùblica algunas casas encuestadoras - afirma Villamil - formaron parte de la estrategia propagandística de Enrique Peña Nieto.

"Supervisado directamente por Pedro Torres y por Alejandro Quintero a través de su representante Montserrat Barrios, el Proyecto Jorge fue de alta confidencialidad. Para Televisa constituyó el secreto mejor guardado porque en él están las huellas de toda su intervención a favor de Peña Nieto en la campaña de 2012. Para Peña Nieto y su equipo fue oficialmente inexistente. La clave del Proyecto Jorge es que no debía dejar huella fiscal ni contable. No hay facturas, no hay contratos. El dinero se manejó en efectivo (...) En el Proyecto Jorge trabajó también la publicista Ana María Olabuenaga, así como la responsable del manejo de redes sociales de Peña Nieto, Alejandra Lagunes, ex directiva de Google México y de Grupo Televisa" (Villamil 2012, pág. 41).

En el proceso de elección interna del candidato presidencial del PAN, Ernesto Cordero, el "delfín” del presidente Felipe Calderón resultó vapuleado por Josefina Vázquez Mota. Las campañas internas resultaron sumamente desgastantes para el PAN. Los panistas lamentablemente exhibieron el cobre. No pocos militantes y simpatizantes del partido blanquiazul advirtieron el obvio distanciamiento de Felipe Calderón, quien como no logró imponer a Ernesto Cordero como candidato del PAN a la presidencia de la República, sencillamente abandonó a su suerte a Josefina Vázquez Mota.

En cuanto a la izquierda, Andrés Manuel López Obrador venía recorriendo el país desde el inicio del gobierno de Felipe Calderón. Sin embargo, Marcelo Ebrard, titular del gobierno en el Distrito Federal, gozaba de amplias simpatías en el Partido de la Revolución Democrática. Ebrard era considerado como un político vanguardista. Sin embargo, López Obrador finalmente consiguió convencer a Marcelo Ebrard, quien finalmente optó por declinar a sus aspiraciones como candidato a la presidencia. De ese modo, por segunda ocasión consecutiva Andrés Manuel López Obrador fue el candidato de la izquierda a la presidencia de la República, en esta ocasión por la 
Coalición Movimiento Progresista, integrada por el Partido de la Revolución Democrática (PRD), Partido del Trabajo (PT), Movimiento Ciudadano (MC).

Durante los primeros días de mayo fue incorporado a YouTube el video La verdad de Peña Nieto en Twitter ${ }^{5}$, el cual ofreció evidencias de las operaciones emprendidas por grupos de twitteros que participaron en la campaña de Enrique Peña Nieto ${ }^{6}$, quienes por consigna maniobraban para restar fuerza a "hash tags" y "trending topics" adversos a Peña Nieto, replicando por consigna determinados lemas de campaña que les eran indicados, como: "es momento de México". En la campaña presidencial de Enrique Peña Nieto se realizó un amplio y costoso proselitismo a través de las redes sociales. Alejandra Lagunes manejó la comunicación de Peña Nieto a través de las redes sociales. Lagunes además se vio en la necesidad de atenuar los negativos efectos que en la twitósfera azteca produjo un torpe mensaje de José Luis Torre, novio de Paulina - hija de Enrique Peña Nieto - El entonces yerno incómodo del candidato presidencial descalificó a los detractores de Peña Nieto llamándolos: "bola de pendejos que forman parte de la prole y que sólo critican a quien envidian”. Mediante su perfil en Twitter (@ Pau_95Pena), Paulina retuiteó la publicación de su novio. Ese hecho desató una furiosa respuesta ciudadana, a partir del hashtag \#soyprole Lagunes realizó las gestiones necesarias para retirar de Twitter las cuentas de Paulina y su novio. La historia concluyó con un mensaje de Enrique Peña Nieto en Twitter, informando que había reprendido a su hija.

\subsection{EL MOVIMIENTO ESTÉTICO \#YOSOY132}

Hacia mediados de mayo de 2012, Televisa efectivamente había conseguido apartar a Enrique Peña Nieto de incómodos cuestionamientos. Durante su campaña en pos de la presidencia de la República, Peña Nieto sólo había concedido tersas entrevistas a algunas celebridades, así como a comentaristas de sociales, espectáculos y deportes. Sin embargo, la mañana del viernes 11 de mayo, la periodista Carmen Aristegui realizó una aguda e inteligente entrevista a Enrique Peña Nieto, en el espacio informativo que ella conduce en MVs Radio (102.5 FM). La entrevista de Aristegui generó profunda pre-

5. Véase: La verdad de Peña Nieto en Twitter. Disponible en http://www.youtube.com/ watch?v=mcysuT4TygA Fecha de consulta: 28 de septiembre de 2013.

6. De acuerdo con Sergio José Gutiérrez Hernández, creador del Movimiento Nacional de Cibernautas (MNC), 33 mil simpatizantes de Enrique Peña Nieto se coordinaron con el grupo de @ectivistas a cargo de Alejandra Lagunes. 
ocupación en Televisa, y Alejandro Puente Córdoba, entonces presidente de la Cámara Nacional de la Industria de Telecomunicaciones por Cable (Canitec), pagó la inserción de un desplegado que fue publicado el lunes 15 de mayo en algunos de los principales diarios nacionales. El entonces presidente de la Canitec, organismo que responde a los intereses de Grupo Televisa, calificó como ofensivas algunas de las preguntas que la periodista formuló al candidato de la Coalición Compromiso por México. En el desplegado Puente además calificó a Aristegui como "cabildera" del empresario Carlos Slim, de Telmex y Telcel"'. Ese mismo día Aristegui, a través de su espacio informativo en Mvs Radio ${ }^{8}$, dio puntual respuesta al contenido del desplegado de Puente.

Poco minutos después de la entrevista que Enrique Peña Nieto sostuvo con Carmen Aristegui, el candidato presidencial del PRI y el Partido Verde asistió a un acto de campaña en la Universidad Iberoamericana (UIA), propiedad de la Compañía de Jesus. Enrique Paña Nieto arribó a la Ibero a las 10:15 horas. Todo permitía suponer que el acto, que formaba parte de las jornadas "Buen Ciudadano Ibero", en las cuales ya se había contado con la asistencia de Andrés Manuel López Obrador, no le representaría dificultad alguna al candidato presidencial del PRI y el PVEM. No fue así. Para los simpatizantes de Peña Nieto - @ectivistas declarados y $\operatorname{confesos}^{9}$ - habían sido reservadas las primeras filas del auditorio José Sánchez Villaseñor, tal como había exigido el equipo de campaña del candidato de la Coalición Compromiso por México. Sin embargo, algunos estudiantes de la UIA decidieron descomponerle el guión a Enrique Peña Nieto. Dentro del auditorio, alrededor de 100 personas alzaron pancartas objetando la presencia de Peña Nieto en la Universidad Iberoamericana. Además, afuera del auditorio más de 800 estudiantes protestaban. Algunos testigos afirman que miembros del equipo de campaña del candidato presidencial ofrecieron entre 250 y 500 pesos a los estudiantes para no levantar carteles en contra del candidato y abstenerse de formularle preguntas incómodas. Ello irritó aún más a los asistentes. El candidato presidencial del PRI fue objeto de duros e

7. Disponible en: http://www.radioformula.com.mx/notas.asp?Idn=244827 Fecha de consulta: 28 de septiembre de 2013.

8. ¿Qué le dolió a Televisa?: Carmen Aristegui. Disponible en: http://www.youtube.com/ watch?v=MeK2bG4TN2Q\&feature=relmfu Fecha de consulta: 28 de septiembre de 2013.

9. Título adoptado por los grupos juveniles que simpatizaban con Enrique Peña Nieto durante su campaña. 
inesperados cuestionamientos por parte de los estudiantes ${ }^{10}$. Además Peña Nieto se vio en la necesidad de huir penosamente del recinto universitario.

En respuesta a lo sucedido, algunos de los principales directivos del PRI, como Pedro Joaquín Coldwell, entonces presidente del Comité Ejecutivo Nacional de ese partido; Emilio Gamboa, secretario general de la Confederación Nacional de Organizaciones Populares, y Arturo Escobar, vocero del Partido Verde Ecologista de México, calificaron a los estudiantes de la UIA como fascistas, intolerantes, porros, acarreados y provocadores. José Carreño Carlón ${ }^{11}$, entonces profesor de la UIA, quien durante el gobierno del presidente Carlos Salinas de Gortari (1988-1994) se desempeñó como responsable de la Dirección General de Comunicación Social de la Presidencia de la República, en una entrevista en Radio Fórmula declaró al periodista Joaquín López Dóriga que quienes cuestionaron a Enrique Peña Nieto seguramente no eran estudiantes de la Ibero o que estaban entrenados por un grupo político. Ese mismo día los hashtags \#MeEscondoEnBañoComoEPN y \#EPNlaIBEROnoTEquiere encabezaron los trending topics en México. Tras los cuestionamientos recibidos en la UIA, Enrique Peña Nieto no volvió a asistir durante su campaña a ningún acto público en ninguna universidad.

Algunos medios de comunicación que nunca han ocultado sus simpatías al PRI, como la Organización Editorial Mexicana, del empresario mueblero Mario Vázquez Raña - quien tanto debe al ex presidente Luis Echeverría Álvarez - presentaron, como en los peores días de la llamada "Presidencia Imperial" (1929-2000), una versión de los hechos diametralmente opuesta a lo ocurrido ${ }^{12}$. En sus respectivos espacios informativos, las dos principales cadenas de televisión en México (Televisa y TV Azteca), minizaron los hechos. Además, algunos de los profesores de la UIA que participaban en espacios informativos en Televisa, particularmente en Foro TV, optaron por una vergonzosa autocensura. La censura y la autocensura observadas por

10. Las neuróticas expresiones de la dirigencia priista por los cuestionamientos de que fue objeto Enrique Peña Nieto en su visita a la Universidad Iberoamericana, sin duda alguna admiten un extraordinario paralelismo con las descalificaciones expresadas por Alejandro Puente a la destacada periodista Carmen Aristegui. El candidato de los "poderes fácticos" no debería ser tocado ni con el pétalo de una rosa.

11. Con el nuevo gobierno del presidente Enrique Peña Nieto (2012-2018), José Carreño Carlón fue designado titular del Fondo de Cultura Económica.

12. Véase el video Huida de Peña Nieto de la Ibero. Disponible en: http://www.youtube.com/ watch? $\mathrm{v}=3 \mathrm{OV}$ oA8t1PfA Consultado: 28 de septiembre de 2013. Véase además: Reacción de Enrique Peña Nieto al salir del baño de la Ibero. Disponible en http://www.youtube.com/watch?v=6mYLjiP $35 z \mathrm{~s}$ Consultado: 28 de septiembre de 2013. 
algunos medios de comunicación naturalmente se convirtieron en uno de los principales ejes de protesta del movimiento \#YoSoy132.

El lunes 14 de mayo de 2012, en respuesta a los inoportunos calificativos que fueron expresados por la alta dirigencia priista, 131 estudiantes de la Universidad Iberoamericana decidieron dar a conocer un video, a través de YouTube: 131 Estudiantes de la Ibero responden a Coldwell: No somos "pseudoestudiantes". En el mencionado video, 131 estudiantes de la UIA ofrecieron información detallada que efectivamente permite confirmar su condición de alumnos de tan reconocida casa de estudios ${ }^{13}$ - despejando de paso las dudas que el maestro Carreño Carlón tenía sobre su procedencia - Precisamente de ese video derivó el Movimiento \#YoSoy132. Además esa misma noche el periodista Circo Gómez Leyva exhibó el video del movimiento estético \#YoSoy132 en su espacio informativo en Milenio Televisión. Ese día el hashtag \#YoSoy132 se convirtió en un trending topic a nivel mundial. Como parte de las operaciones destinadas al control de daños, un grupo de simpatizantes de Peña Nieto puso en circulación un video en el cual supuestos estudiantes de la UIA - que en realidad eran ectivistas egresados del Instituto Tecnológico Autónomo de México (IтAM) - fueron presentados como estudiantes de la UIA. En el referido video los entrevistados comentaban positivamente la visita de Enrique Peña Nieto a su universidad ${ }^{14}$.

El martes 13 de mayo, José Morales Orozco, rector de la UiA Santa Fe, mediante un comunicado dirigido a la comunidad universitaria, defendió a los estudiantes ante las acusaciones realizadas por distinguidos miembros del PRI como del Partido Verde. Mientras tanto en las redes sociales el tema \#Soy132 empezó a ser asociado con el desarrollo mismo de la elección presidencial, descendiendo significativamente la popularidad del candidato Enrique Peña Nieto. El jueves 17 de mayo de 2012, el movimiento \#YoSoy132 se había convertido en el principal tema informativo en el desarrollo de las campañas presidenciales. Además al movimiento estético se habían sumado un amplio número de universidades públicas como privadas.

El viernes 18 de mayo, el movimiento \#YoSoy132 realizó sus primeras marchas de protesta. La principal, desde la Universidad Iberoamericana a las instalaciones de Televisa, en Santa Fe. En la segunda marcha, alumnos del IтAм caminaron desde esa universidad a las instalciones de Televisa San

13. Véase: 131 Estudiantes de la Ibero responden a Coldwell: No somos “pseudoestudiantes". Disponible en http://www.youtube.com/watch?v=1iZp5ThcH8M Fecha de consulta: 4 de junio de 2012.

14. Véase: El PRI usa a ex alumnos del ITAM para defender a Peña Nieto. Disponible en: http://www. youtube.com/watch?v=qcKn6AqPnUs Consultado: 28 de septiembre de 2013. 
Ángel. En el recorrido algunos de los marchistas gritaron: "No somos porros, somos estudiantes", "!Televisa te idiotiza!", “!TV Azteca te apendeja!", "!No somos uno, no somos diez, prensa vendida, cuéntanos bien!", "Prensa, no te vendas". Ese día los hashtags \#YoSoy132 y Marcha\#YoSoy132 figuraron entre los primeros trending topics mundiales. Además reconocidos académicos e intelectuales, actores y músicos se pronunciaron a favor del movimiento. Esa noche finalmente las televisoras comprendieron que no podían seguir ignorando las acciones realizadas por el movimiento \#YoSoy132, y se vieron en la necesidad de referir las marchas realizadas ese día en sus principales espacios informativos.

Una burda y oportunista maniobra con la que pretendió dividirse al estudiantado corrió a cargo de algunos alumnos de la Universidad Etac - escuela de dudosa reputación, ubicada en el Estado de México - , quienes produjeron un video relativamente similar al realizado por los estudiantes de la UIA, pero afirmando su simpatía por Enrique Peña Nieto: "No somos $131 \mathrm{ni}$ 132, decimos sí a Enrique Peña Nieto". Ese video fue objeto de una amplia cobertura en determinados medios informativos, Milenio, por ejemplo. En el mencionado video, que tenía una duración de un minuto con 29 segundos, 10 estudiantes de la Universidad Etac exhibieron sus credenciales para acreditarse como miembros de la referida institución educativa, procediendo a afirmar sus simpatías al ex gobernador del Estado de México:
"Cuando él esté en la Presidencia nos va a devolver a los mexicanos lo que hemos perdido, la esperanza. Gracias por no gastar tu campaña en ataques y descalificaciones, por apoyar la libertad de expresión de los jóvenes y no se nos olvide que durante tu gobierno creaste 22 campos universitarios". ${ }^{15}$

El sábado 19 de mayo, el movimiento \#YoSoy132, a través de las redes sociales, convocó a una gran manifestación pública que se llevaría a cabo el miércoles 23 de mayo en la llamada Estela de Luz ${ }^{16}$, a las 18 horas, para

\footnotetext{
15. Véase: http://www.milenio.com/cdb/doc/noticias2011/e76a7d71d362008321e3bedac3e5e794 Fecha de consulta: Consultado: 28 de septiembre de 2013.

16. El miércoles 23 de mayo, el Movimiento Yo soy 132 realizó un acto de profundo significado simbólico, en la Estela de Luz, en la Ciudad de México. Dado el elevadísimo costo que representó construir el referido monumento, destinado a conmemorar el bicentenario de nuestra independencia y el centenario del inicio de la Revolución Mexicana, la Estela de Luz ha sido considerada como uno de los símbolos emblemático de la corrupción panista. Manifestaciones similares fueron realizadas en otras ciudades
} 
protestar por la desinformación y el favoritismo observado hacia Peña por determinados medios informativos. Además del acto realizado en la Ciudad de México, simpatizantes del movimiento se dieron a la tarea de organizar actos similares en algunas de las principales ciudades en el país, como Aguascalientes, Cancún, Coahuila, Guadalajara, Guanajuato, Morelia, Oaxaca, Pachuca, Puebla, Querétaro, Saltillo, Tijuana, Villahermosa. De acuerdo con Jenaro Villamil:

"En la Ciudad de México más de 40 mil personas, la mayoría jóvenes, marcharon del Zócalo al Ángel de la Independencia. En Guadalajara, Monterrey y Puebla se dieron las concentraciones más numerosas. Los organizadores defendieron el término \#YoSoy132, en contra de la denominación \#MarchaAntiEPN que fue inundada de miles de bots desde diferentes partes de Sudamérica para que no se convirtiera en trending topic. Fue la primera gran manifestación convocada desde las redes sociales (en Facebook se creó la página \#YoSoy132) que se generalizó en todo el país y en decenas de ciudades con presencia mayoritaria de jóvenes. Las principales consignas en esa marcha fueron contra Peña Nieto, Televisa y las encuestas, en ese orden. También se planteó la exigencia de una "cobertura mediática imparcial”. México 2012 no es una producción televisiva, resumió una de las mantas más grandes ${ }^{17}$.

Hasta ese día parecía inconcebible poder convocar en México una manifestación pública a través de las redes sociales. Con anterioridad, a través de flash moves francamente ingenuos e intrascendentes, algunos internautas habían intentado estimular la participación de los internautas, consiguiendo reunir en determinados actos a no más de 40 personas. Las clases medias, cuyo activismo fue definitivo en el triunfo de Vicente Fox, en el año 2000, de nueva cuenta incursionaron en las calles y avenidas en algunas de algunas de las principales ciudades. La imaginación crítica - que algunos suponían ajena a los estudiantes de universidades privadas - había conseguido poner en graves predicamentos a Enrique Peña Nieto, a Televisa, y demás socios e instituciones que de facto ya rendían al mexiquense el trato de presidente en

del país. La organización de tales actos partió de las redes sociales.

17. Véase: http://www.sinembargo.mx/28-05-2012/246176. Consultado: 28 de septiembre de 2013. 
funcione ${ }^{18}$. El Movimiento Soy 132 afirmó la capacidad de convocatoria ciudadana de las redes sociales:

"El miércoles 23 se realizó la segunda marcha del movimiento \#YoSoy132, también convocada mediante las redes sociales, que partió de la Estela de Luz, en la avenida Reforma. Surgió la cuenta en Twitter y el blog www.YoSoy132.mx donde subrayan que se trata de un movimiento "apartidista" y que está en contra de la manipulación mediática. Seguros de la fuerza que han adquirido las redes sociales, los integrantes de este movimiento, surgido en las universidades de todo el país, advierten: "Evitemos los riesgos de ser diluidos por los bots en Twitter, denunciados de spam o infracciones en Youtube, o poner en riesgo nuestros perfiles personales de Facebook. Desde esta plataforma de YoSoy132.mx podremos concentrar nuestras propuestas, ideas y reclamos para que sean vistos y escuchados por todos. El poder está en nuestras manos, no perdamos la oportunidad de hacer y cambiar la historia de nuestro país". AHORA, LAS REDES". ${ }^{19}$

El miércoles 30 de mayo de 2012 fue un día que estableció un parteaguas en el desarrollo del movimiento. Ese día, en las instalaciones de la Universidad Nacional Autónoma de México (UNAM), se realizó la primera asamblea general del movimiento \#YoSoy132, en la cual participaron 6,500 estudiantes de 54 universidades. El movimiento se declaró apartidista, plural, independiente, pacífico y contrario a la imposición de cualquier candidato a la presidencia de la República, particularmente Enrique Peña Nieto. Ese día \#YoSoy132 adquirió las cualidades de un moviento político, con amplia presencia nacional y con miles de seguidores.

En tan solo 10 días el candidato a la presidencia de la República por la Coalición Compromiso por México se enfrentaba un escenario definitivamente inesperado: la viralidad del movimiento \#YoSoy132, el cual desplazó a un plano secundario las campañas que venían realizando los candidatos presidenciales. Como atinadamente advierten Jesús Galindo y José Ignacio González-Acosta:

18. Debemos tener muy presente que en su visita al Tecnológico de Monterrey, campus Monterrey, Andrés Manuel López Obrador, el candidato de las izquierdas, fue objeto de una cálida y emotiva recepción por parte de los estudiantes del Tec de Monterrey.

19. Idem 


\begin{abstract}
"En tan solo diez días, este movimiento impacta seriamente la imagen de Enrique Peña Nieto, candidato del PRI-PV y borra el impetú de su campaña, con tal fuerza que lo deja sin tema y su candidatura debilitada frente a un aventajado Andrés Manuel López Obrador" (Galindo y González 2012, pág 24).
\end{abstract}

Efectivamente, en tan solo 10 días el movimiento estético \#YoSoy132 había opacado las campañas presidenciales. Para compensar tal situación, los responsables de la propaganda en nuevos medios digitales de Josefina Vázquez Mota decidieron apostar por la burda compra de seguidores en redes sociales. También contrataron bots que fueron destinados a replicar mensajes de la grisácea candidata, y por supuesto trolls que se dedicaron a ofender y descalificar a toda aquella persona que realizara algún cuestionamiento o crítica a Josefina a través de las redes sociales ${ }^{20}$. Para el equipo de campaña de Andrés Manuel López Obrador, las redes sociales nunca representaron un asunto estratégico. Sin una estrategia definida y con muy pocos recursos, los simpatizantes de Andrés Manuel López Obrador, improvisaban a su entender acciones y respuestas. La principal amenaza de Peña Nieto, como atinadamente comprendió Luis Videgaray, uno de los principales asesores del priista, radicaba en la formidable viralidad del movimiento \#YoSoy132:

"Estamos perdiendo la batalla en las redes sociales", sentenció Luis Videgaray, coordinador general de la campaña de Peña Nieto, en la última reunión del "cuarto de guerra" tricolor. $\mathrm{Ni}$ los spots, ni la inversión millonaria en publicidad en internet, ni el ejército de @ectivistas ni la creación de páginas on line dedicadas a promover al candidato más telegénico en la historia del PRI, han podido modificar la ola creciente de descontento que se expresa en los nuevos medios convergentes, donde no cuenta tener el mayor número de seguidores, sino los mensajes más convincentes. El nerviosismo también ha cundido en Televisa, el gigante de los medios de comunicación en México, que se enfrenta a las protestas de miles de universitarios de entre 18 y 24 años que gritan en las calles: "Televisa te idiotiza" y “¡Fuera Televisa!”. La televisora primero ignoró, luego minimizó, descalificó como "promotores de la dictadura del odio" y ahora

20. Empresas como Shopatia.Com, BuyFollowers.org y BootsTwitterFollowers.com cobraban entre 2,500 y 75 mil dólares por vender cuentas de seguidores en redes sociales. 
quiere congraciarse con grupos de jóvenes, especialmente los usuarios de Twitter, que han protagonizado las críticas más ácidas contra Televisa y TV Azteca. Incluso, Ricardo Salinas Pliego, concesionario de la segunda televisora más grande, llegó a descalificar a sus críticos como "un grupito de twitteros autoritarios". No entienden y no saben qué hacer con estas audiencias que ya no se formaron en la cultura televisiva (...) Los asesores originales del equipo de Peña Nieto, provenientes de la empresa Inc Slingers, le recomendaron desde principios de 2011 que no buscara mayor número de seguidores, sino un manejo más directo y deliberativo de las redes sociales. De acuerdo con testimonios recabados en el PRI, Inc Slingers fueron desplazados por el equipo de Alejandra Lagunes, quien trabajó en Presidencia durante el sexenio de Ernesto Zedillo, en Yahoo, en Microsoft, en Google y en Televisa. Su principal actividad en estos gigantes del internet era la publicidad y las ventas. Lagunes se hizo cercana al entorno peñista cuando trabajó con Luis Videgaray en la campaña de Eruviel Ávila como candidato a gobernador del Estado de México. Su principal carta de presentación, antes de ser la responsable de la estrategia en redes sociales, fue el cargo que tuvo como directora general comercial de Televisa Interactive Media, y su amistad con Emilio Azcárraga Jean”. ${ }^{21}$

\section{LA ESTÉTICA DE SOY 132}

"En general, las instituciones han perdido su capacidad de generar participación e invlucramiento social; los movimientos sociales organizados (campañas politicas, sindicales, gremiales) sólo cautivan a una fracción de sus públicos metas; los líderes han perdido su poder de convocatoria; salvo excepciones, los medios de comunicación son incapaces de establecer agendas de discusión pública. En paralelo, en México empiezan a gestarse estallidos sociales con gran poder de convocatoria. Amplia participación y profundos niveles de involucramiento. Son movimientos estéticos, los que poseen tal nivel de encanto". (Galindo, J., y González. J.)

21. Véase: http://www.sinembargo.mx/28-05-2012/246176. Consultado: 28 de septiembre de 2013. 
En 1969, en el libro Un ensayo sobre la revolución (1969), Marcuse destacó la importancia de la nueva estética revolucionaria. Marcuse comprendía que la ciencia y la tecnología pueden convertirse en vehículos de libertad: "tendrían que cambiar su dirección y metas actuales; tendrían que ser reconstruidas con una nueva sensibilidad: la de las exigencias de los instintos vitales. Entonces se podrá hablar de una tecnología de liberación" (Marcuse 1969, pág. 28). La "nueva sensibilidad" - anticipaba Marcuse - se ha convertido en una nueva fuerza política.

"La nueva sensibilidad, que expresa la afirmación de los instintos de vida sobre la agresividad y la culpa, nutriría, en una escala social, la vital urgencia de la abolición de la injusticia y la misería, y configuraría la ulterior evolución del nivel de vida. Los instintos de vida encontrarían expresión racional (sublimación) en el planeamiento de la distribución del tiempo de trabajo socialmente necesario dentro y entre las varias ramas de la producción, deteminando así prioridades de objetivos y selecciones: no sólo lo que se debe producir, sino también la forma del producto. La conciencia liberada promovería el desarrollo de una ciencia y una tecnología libres para descubrir y realizar las potencialidades de las cosas y de los hombres en la producción y el goce de la vida, jugando con las potencialidades de forma y materia para el alcance de esta meta. La técnica tendería entonces a devenir arte y el arte tendería a formar la realidad: la oposición entre imaginación y razón, entre altas y bajas facultades, entre pensamiento poético y científico, sería invalidada. Aparecerìa asún un nuevo Principio de Realidad, bajo el que se combinaría una nueva sensibilidad y una inteligencia científica desublimada para la creación de un ethos estético. El término estético, en su doble connotación de perteneciente a los sentidos y perteneciente al arte, puede servir para designar la cualidad del proceso productivo creativo en un medio ambiente de libertad (Marcuse 1969, págs. 32-33).

La nueva sensibilidad además es praxis:

"emerge en la lucha contra la violencia y la explotación, allí donde esta lucha se encamina a lograr modos y formas de vida esencialmente nuevos: negación total del sistema establecido, 
de su moralidad y su cultura; afirmación al derecho a construir una sociedad en la que la abolición de la violencia y el agobio desemboque en un mundo donde lo sensual, lo lúdico, lo sereno y lo bello lleguen a ser formas de existencia y, por tanto, la Forma de la sociedad misma" (Marcuse 1969, pág. 34).

De acuerdo con Jesús Galindo y José Ignacio González-Acosta, las principales características de todo movimiento estético son: 1. Apelan a nuevas identidades; 2. Saben cómo usar los medios que importan; 3. Son auténticos. Los movimientos estéticos, se distinguen de los movimientos políticos tradicionales por no polarizar entre estar a favor o en contra, sino por distanciar lo sublime de lo vulgar, lo honesto o lo deshonesto, lo bello o lo repugnante, lo legítimo o lo ilegítimo, lo justo o lo injusto, lo digno o lo indigno, la libertad o la opresión, lo moral o lo inmoral, la libertad o la coacción, la conciencia o la ignorancia, lo que ofende o lo que enaltece, más de lo mismo o cambio, lo moderno y lo fuera de moda (Galindo y González 2012, pág. 106).

Estos son algunos ejemplos del ethos estético del movimiento \#YoSoy132, en las redes sociales:

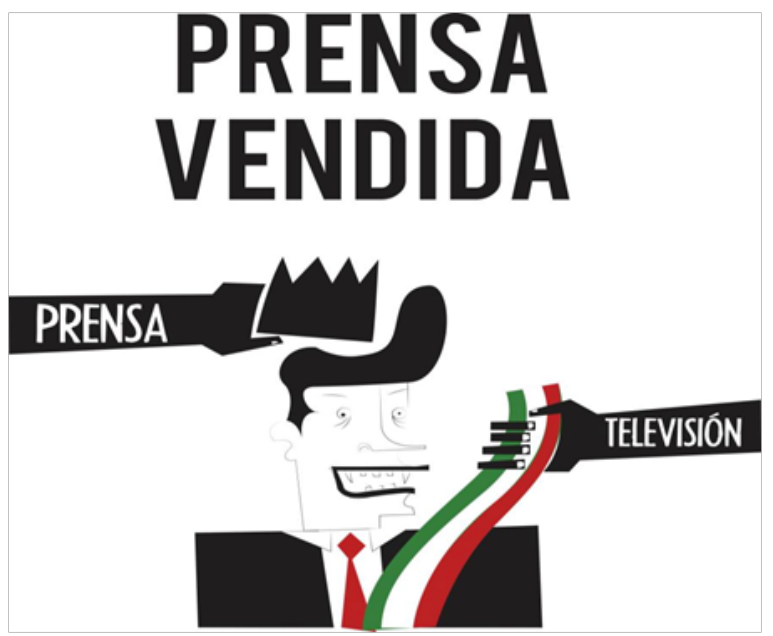

FIGURA 1. NOTA. LA PRENSA Y LA TELEVISIÓN DIERON TRATO DE PRESIDENTE ELECTO A ENRIQUE PEÑA NIETO, CANDIDATO DE LA COALICIÓN COMPROMISO POR MÉXICO. 


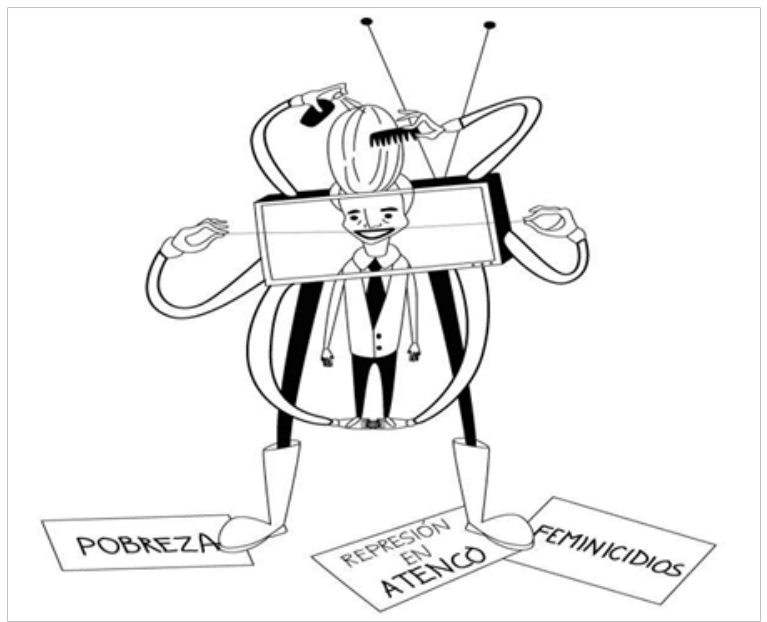

FIGURA 2. NOTA. TELEVISA MAQUILLÓ LA IMAGEN PÚBLICA DE ENRIQUE PEÑA NIETO, OCULTANDO INFORMACIÓN SOBRE DETERMINADOS HECHOS QUE FUERON OBJETO DE AMPLIOS CUESTIONAMIENTOS DURANTE LA GESTIÓN DE PEÑA NIETO COMO GOBERNADOR DEL ESTADO DE MÉXICO, COMO LA POBREZA EN LA ENTIDAD, LA REPRESIÓN EJERCIDA CONTRA LOS HABITANTES EN ATENCO Y EL ALARMANTE NÚMERO DE FEMINICIDIOS.

FEMINICIDIOS EN EL ESTADO DE MÉXICO.

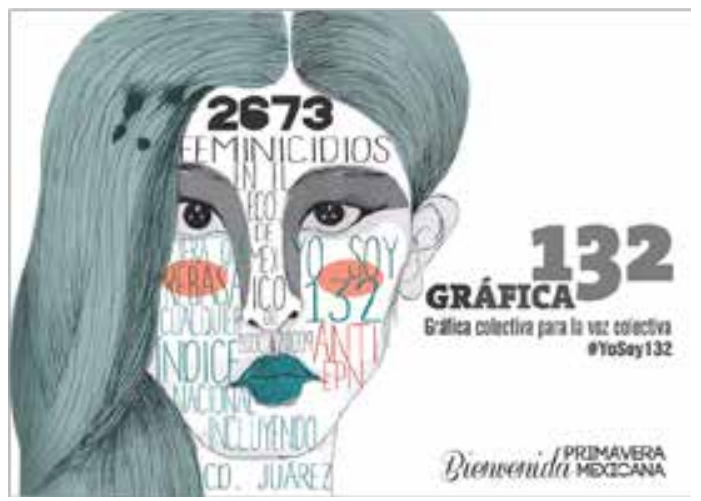

FIGURA 3. NOTA. 2,673 FEMINICIDIOS EN EL ESTADO DE MÉXICO DURANTE LA GESTIÓN DE ENRIQUE PEÑA NIETO COMO GOBERNADOR. 
O. ISLAS

APÁGALA Y AVANZA

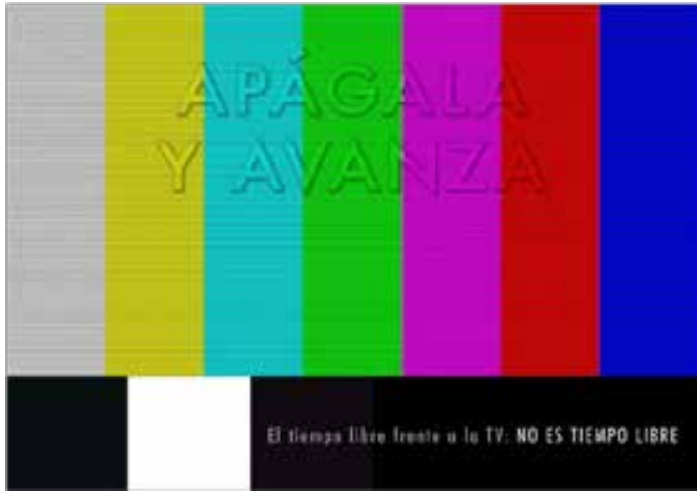

FIGURA 4. NOTA. VER TELEVISIÓN ES PERDER EL TIEMPO.

\#YOSOY132

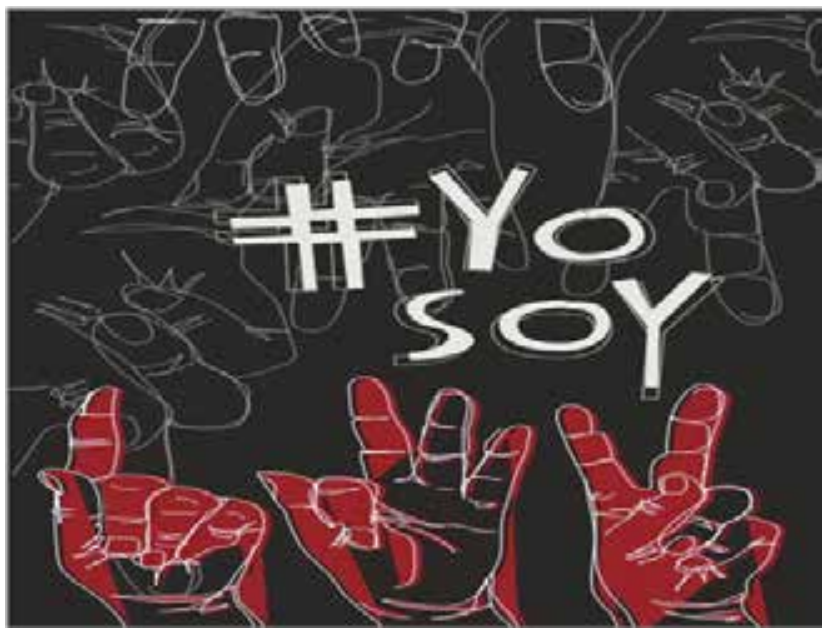

FIGURA 5. NOTA. EN LA FIRMEZA DE NUESTROS PUÑOS AFIRMAMOS NUESTRA IDENTIDAD.

96 | ISSN 1696-2079 
VOTA LIBRE E INFORMADO POR UN MÉXICO MEJOR

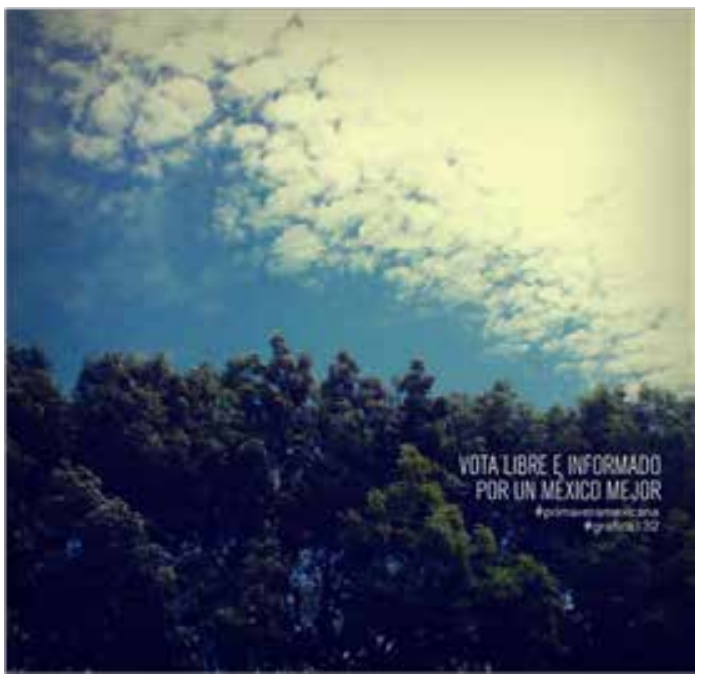

FIGURA 6. NOTA. LA PRIMAVERA MEXICANA.

VOTAR ES...

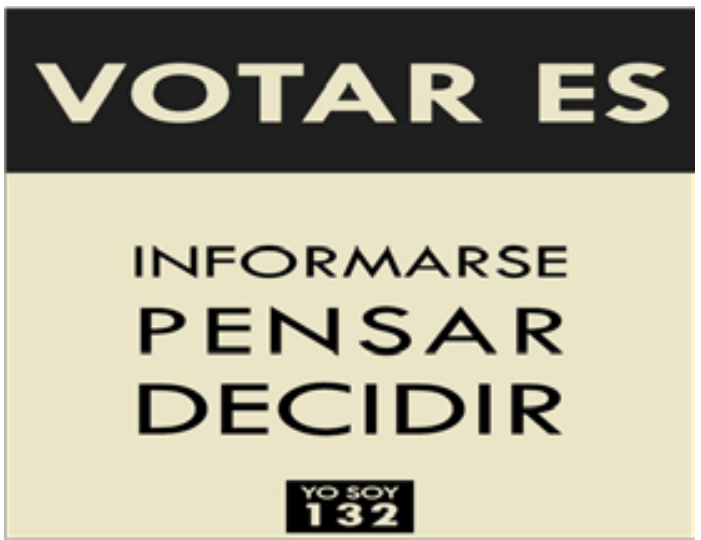

FIGURA 7. NOTA. PROMOCIÓN DEL SUFRAGIO INTELIGENTE. 


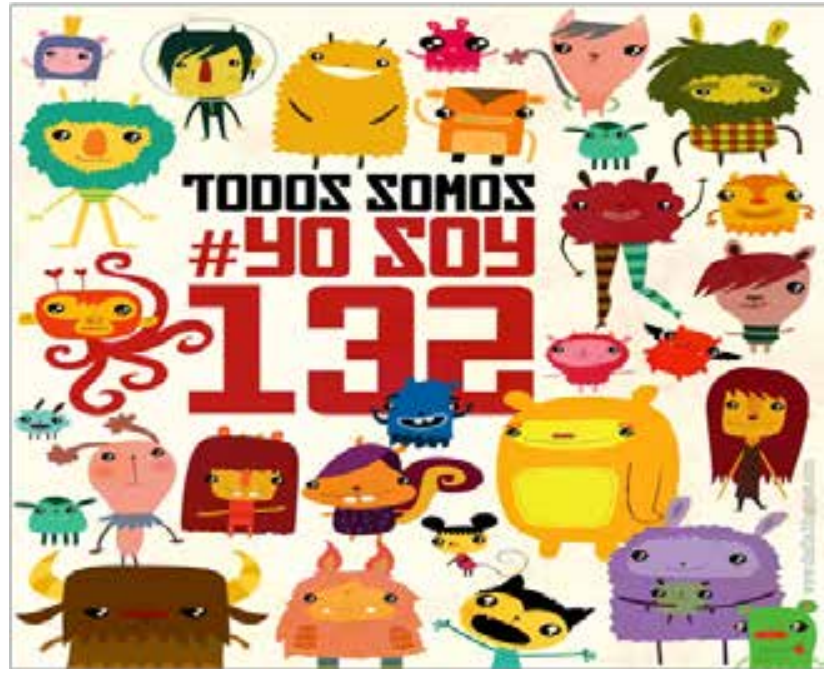

FIGURA 8. NOTA. AFIRMACIÓN DE LA DIVERSIDAD

LIBÉRATE

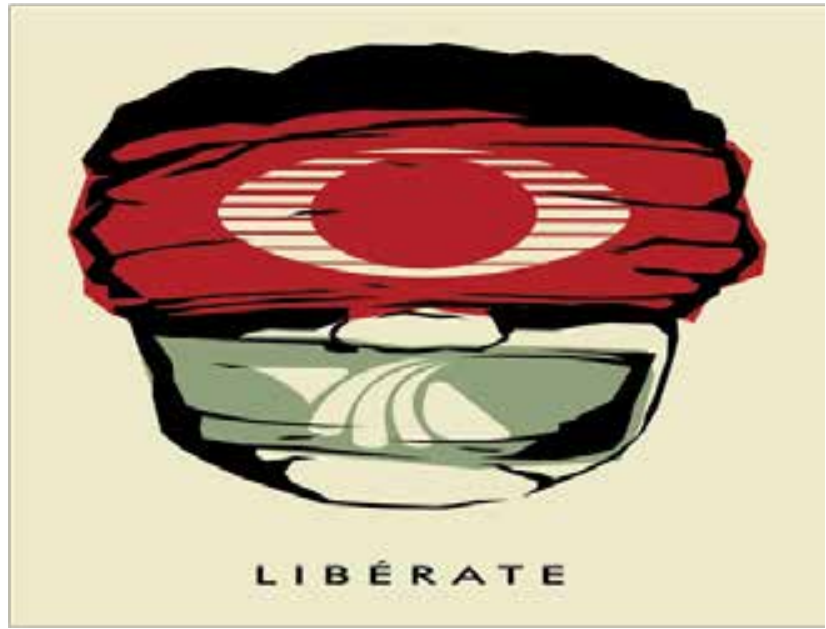

FIGURA 9. NOTA. LIBÉRATE DE TELEVISA Y TV AZTECA. 
NO AL VOTO POR DESPENSA.

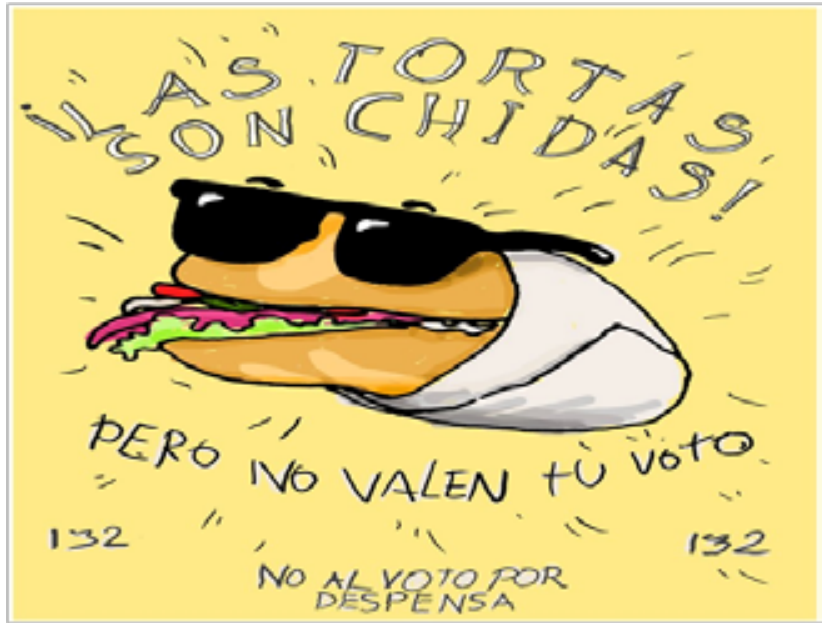

FIGURA 10. NOTA. CONTRA LA COMPRA DE VOTOS POR ALIMENTOS...

TODO ES MEJOR

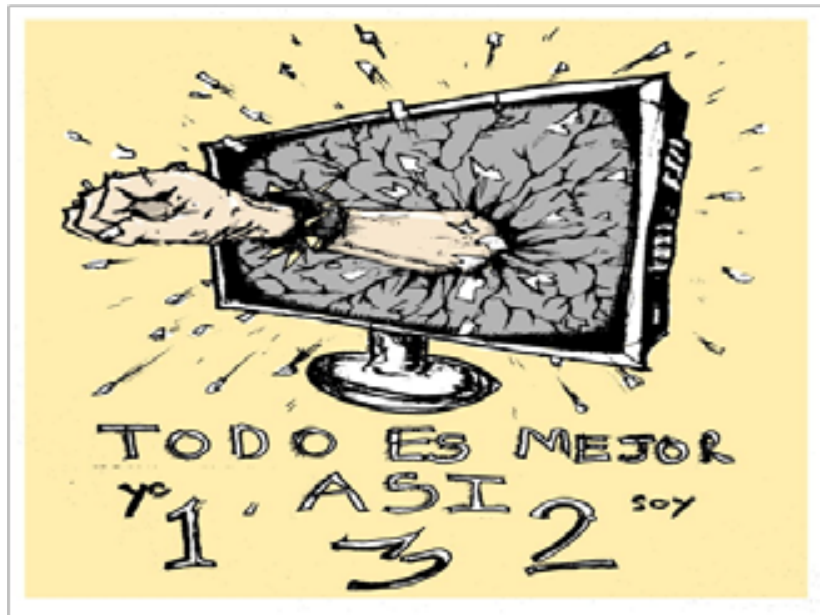

FIGURA 11. NOTA. LA NECESIDAD DE ROMPER CON EL ORDEN ESTABLECIDO A TRAVÉS DEL TELEVISOR. 


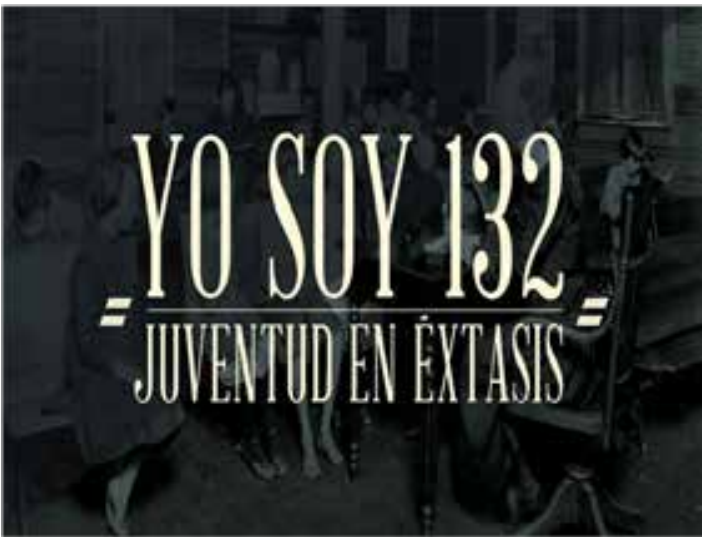

FIGURA 12. NOTA. LA UTOPÍA PUEDE SER POSIBLE

MIRA DENTRO DE TI

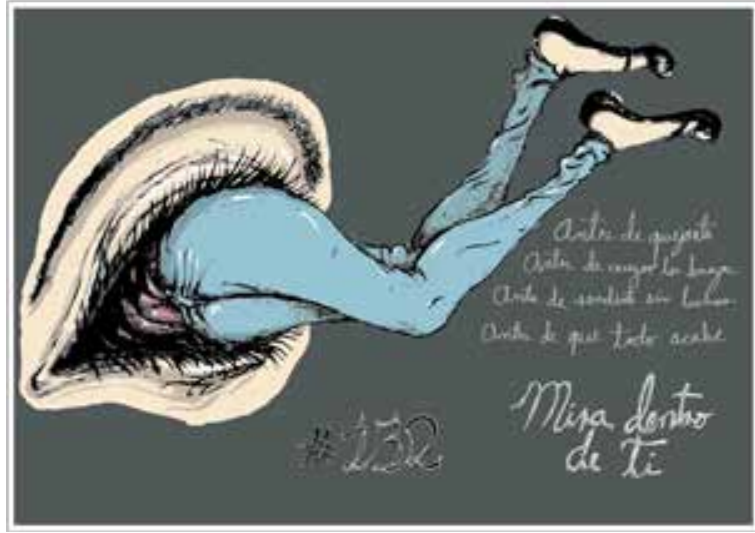

FIGURA 13. NOTA. LA POÉTICA DE LA NUEVA SENSIBILIDAD

Con base en algunos señalamientos de Marcuse y ¿por qué no?, rescatando las utopías posibles, podemos concluir que el movimiento \#YoSoy132 efectivamente afirmó la esperanza de la profunda e indispensable reconstrucción de México:

"La nueva sensibilidad y la nueva conciencia que han de proyectar y guiar tal reconstrucción exigen un nuevo lenguaje 
para definir y comunicar los nuevos "valores" (un lenguaje en el sentido más amplio, que incluye palabras, imágenes, gestos, tonos). Se ha dicho que el grado en que una revolución va desarrollando condiciones y relaciones sociales cualitativamente diferentes puede quizás sernos in-dicado por el desarrollo de un lenguaje diferente: la ruptura con el continuum de la dominación debe ser también una ruptura con el vocabulario de la dominación. La tesis surrealista, de acuerdo con la cual el poeta es el inconformista total, encuentra en el lenguaje poético los elementos semánticos de la revolución". (Marcuse 1969, pág. 39).

\section{POR Último}

Durante el último mes de campañas (junio de 2012), algunas casas encuestadoras dieron a conocer resultados de encuestas que concedían a Peña Nieto una diferencia de 15 puntos sobre Andrés Manuel López Obrador, el candidato presidencial más próximo, quien finalmente rebasó a Josefina Vázquez Mota, la candidata del partido que estaba al frente del gobierno. Tales cifras respondían al propósito de desalentar el voto por otros candidatos, promoviendo el eventual triunfo de Enrique Peña Nieto antes de haberse celebrado las elecciones. La ventaja de Peña Nieto sobre López Obrador finalmente fue de un solo dígito (6.87 por ciento). Para asegurar el triunfo de Enrique Peña Nieto en los referidos comicios, mediante intrincadas triangulaciones fueron repartidas tarjetas y vales de despensa de los almacenes Soriana a los promotores del voto peñista. De acuerdo con un reporte realizado por miembros de \#YoSoy132, la compra de sufragios fue realizada de la siguiente manera:
"un coordinador recibe 2,000 pesos por llevar a 15 promotores del voto, los cuales se comprometen a sacar su boleta en blanco y dársela a su coordinador para que la marque a favor del PRI y que la siguiente persona la regrese a la misma casilla como voto propio. Asimismo, esta persona saca nuevamente la boleta y se la da al coordinador. La operación se repite así consecutivamente" (Villamil 2012, pág. 19).

Además el Sindicato Nacional de Trabajadores de la Educación (SNTE), cuya líder vitalicia - la maestra Elba Esther Gordillo, quien también controlaba el Partido Nueva Alianza (PANAL), quien hoy se encuentra en prisión -, desplegó la "Operación Ágora" para asegurar cinco millones de votos por 
Peña Nieto, contando para ello con 20,000 "movilizadores", con un costo estimado en $151,271,750$ pesos.

El domingo 6 de julio de 2012, además de elegir al presidente de la República para el periodo 2012-2018, los ciudadanos votamos para elegir 128 senadores, 500 diputados federales, cinco gobernadores, el jefe de gobierno del Distrito Federal, 16 jefes delegacionales en la Ciudad de México, así como por un amplio número de presidentes muncipales y alcaldes. De acuerdo con el Instituto Federal Electoral (IFE), en la elección del presidente de la República fueron emitidos 50,323,153 sufragios. Participaron 63.94 por ciento de los ciudadanos inscritos en la lista nominal. Estos fueron los resultados que arrojó la elección presidencial:

RESULTADOS PARA LA ELECCIÓN DE PRESIDENTE DE LA REPÚBLICA, 2 DE JULIO

DE 2012

\begin{tabular}{|c|c|c|c|c|c|c|}
\hline $\begin{array}{l}\text { Partido } \\
\text { Acción } \\
\text { Nacional } \\
\text { (pan) }\end{array}$ & $\begin{array}{l}\text { Coalición } \\
\text { Compromiso } \\
\text { por México } \\
\text { Partido } \\
\text { Revolucionario } \\
\text { Institucional } \\
\text { (PRI) } \\
\text { Partido Verde } \\
\text { Ecologista de } \\
\text { México (PVEM) }\end{array}$ & $\begin{array}{l}\text { Coalición } \\
\text { Movimiento } \\
\text { Progresista } \\
\text { Partido de la } \\
\text { Revolución } \\
\text { Democrática } \\
\text { (PRD), } \\
\text { Partido del } \\
\text { Trabajo (PT), } \\
\text { Movimiento } \\
\text { Ciudadano } \\
\text { (Mc) }\end{array}$ & $\begin{array}{l}\text { Partido } \\
\text { Nueva } \\
\text { Alianza }\end{array}$ & $\begin{array}{l}\text { Candidatos } \\
\text { no } \\
\text { registrados }\end{array}$ & $\begin{array}{l}\text { Votos } \\
\text { Nulos }\end{array}$ & $\begin{array}{c}\text { Total } \\
\text { Sufragios }\end{array}$ \\
\hline $\begin{array}{l}\text { Josefina } \\
\text { Eugenia } \\
\text { Vázquez } \\
\text { Mota }\end{array}$ & $\begin{array}{l}\text { Enrique Peña } \\
\text { Nieto }\end{array}$ & $\begin{array}{l}\text { Andrés } \\
\text { Manuel López } \\
\text { Obrador }\end{array}$ & $\begin{array}{l}\text { Gabriel } \\
\text { Ricardo } \\
\text { Quadri de } \\
\text { la Torre }\end{array}$ & & & \\
\hline $12,786,647$ & $19,226,784$ & $15,896,999$ & $1,150,662$ & 20,907 & $1,241,154$ & $50,323,153$ \\
\hline $25.41 \%$ & $38.21 \%$ & $31.59 \%$ & $2.29 \%$ & $0.4 \%$ & $2.47 \%$ & $100 \%$ \\
\hline
\end{tabular}

TABLA 1. FUENTE: INSTITUTO FEDERAL ELECTORAL (2013). 
A finales del mes de septiembre de 2002, el Tribunal Electoral del Poder Judicial de la Federación (TEPJF) calificó la elección presidencial, declarando triunfador a Enrique Peña Nieto, candidato de la coalición Compromiso por México, integrada por el Partido Revolucionario Institucional (PRI) y el Partido Verde Ecologista de México (PVEM). De acuerdo con la suma de los votos legales, la diferencia entre Enrique Peña Nieto y Andrés Manuel López Obrador fueron 3,330,785 votos. Josefina Vázquez Mota, candidata del Partido Acción Nacional (PAN), quedó muy atrás, en el tercer lugar, con 25.41 por ciento de los votos. A pesar de la intensa campaña propagandística desplegada en los medios de comunicación, el número de votos a favor de Gabriel Quadri, candidato del Partido Nueva Alianza $(1,150,662)$ fue inferior al número de votos anulados $(1,241,154)$.

En el desarrollo de las recientes elecciones presidenciales, las redes sociales observaron un rol que definitivamente admite ser considerado como protagónico. Sin embargo, no precisamente fueron los partidos políticos los que evidenciaron el mejor manejo de las redes sociales sino el movimiento \#YoSoy132. Los responsables del desarrollo de las campañas proselitistas en los equipos de campaña de los candidatos presidenciales, sencillamente omitieron observar dos principios fundamentales en la comunicación a través de redes sociales: construir bases de datos efectivamente confiables para el desarrollo de atinadas acciones proselitistas en los nuevos medios sociales, y estimular el desarrollo de verdaderas comunidades de prosumidores simpatizantes con los candidatos o los partidos.

La revuelta reivindicativa de los estudiantes que participaron en el movimiento \#YoSoy132 ha establecido un parteaguas definitivo en el desarrollo de las campañas proselitistas, demostrado la capacidad de movilización ciudadana desde el imaginario de las redes sociales, y anticipando la paulatina extinción de los operadores políticos, cuya función primordial ha sido garantizar la efectiva concurrencia de las "fuerzas vivas" en los mítines y actos públicos de candidatos a puestos de elección ciudadana, a partir de objetables prácticas clientelares. Los estudiantes asumirán un rol protagónico en la transformación del país. Han advertido con notable claridad la gestación de un nuevo orden informativo a partir de los nuevos medios sociales. Los estudiantes comprenden la posibilidad de utilizar las redes sociales para remediar el deteriorado tejido social. Esa es precisamente la nueva utopía posible. 


\section{FUENTES DE INFORMACIÓN}

AMIPCI. Estudio 2012 de hábitos y percepciones de los mexicanos sobre Internet y diversas tecnologías asociadas. Consultado: 11 de febrero de 2013. Disponible en http://www.ampici.org.mx

BEAS, D. (2010). La reinvención de la política. Internet y la nueva esfera política. Buenos Aires: Temas de hoy.

CEPAL - Comisión Económica para América Latina y el Caribe. Sistema de Información Estadístico de TIC. Véase: http://www.eclac.org/tic/Dash

CONSULTA MITOFSKY. Perfil de usuario de redes sociales en Internet: Facebook y Twitter. 2012. Disponible en: http://www.slideshare.net/rperalromea/ redes-sociales-mitofskymultimedia Fecha de consulta: 11 de febrero de 2013.

DURÓ, R. (2005). Política de la ilusión. Buenos Aires: Ediciones del signo.

FERNÁNDEZ, C.; PAXMAN, A. (2000). El Tigre Emilio Azcárraga y su imperio Televisa. México: Grijalbo.

IAB México. Estudio 2011 de hábitos y percepciones de los mexicanos sobre Internet $y$ diversas tecnologías asociadas. Consultado:11 de febrero de 2013. Disponible en https://www.box.com/s/r7fofkqcoyet47thw3kk

INEGI. Estadisticas sobre la disponibilidad y uso de tecnología de información $y$ comunicaciones en los Hogares, 2011. Disponible en: http://www.inegi.org. $\mathrm{mx} /$ prod_serv/contenidos/espanol/bvinegi/productos/encuestas/especiales/endutih/ENDUTIH2011.pdf

MARCUSE, H. (1969). Un ensayo sobre la liberación. México: Cuadernos de Joaquín Mortiz.

MARCUSE, H. (1975). Contrarrevolución y revuelta. México: Cuadernos de Joaquín Mortiz.

MARCUSE, H. (1978). Cultura y sociedad. Buenos Aires: Editorial Sur.

MARCUSE, H. (1984). Razón y revolución. Madrid: Editorial Alianza.

MARCUSE, H. (1986). Ensayos sobre política y cultura. México: Editorial Artemisa.

OCDE - Organización para la Cooperación y del Desarrollo Económico. ICT database and Eurostat, Community Survey on ICT usage in households and by individuals, November 2011.

PINGDOM. Internet in numbers. Disponible en http://royal.pingdom. com/2013/01/16/internet-2012-in-numbers/ Consultado: 11 de febrero de 2013.

Sitio web de la Cámara de Diputados: http://www.diputados.gob.mx Sitio web de la Cámara de Senadores: http://www.senado.gob.mx/index.php 
Sitio web de la Cumbre Mundial de Indignados, disidentes, insurgentes: http://cumbreidi.org/participantes/\#expositores

Sitio web del Instituto Federal Electoral (IFE): http://www.ife.org.mx

Sitio web de la Internet World Stats (IWS): http://www.internetworldstats. com/stats.htm

Sitio web del World Internet Project: http://www.worldinternetproject.net

SWAN, R. (2009). El método Obama. Las 100 claves comunicativas del hombre que ha revolucionado el mundo. México: Debols!illo.

TOFFLER, A. (1981). La Tercera Ola. $1^{\text {a }}$ ED. México: Edivisión.

VILLAMIL, J. (2009). Si yo fuera presidente. El reality show de Peña Nieto. México: Grijalbo.

VILLAMIL, J. (2010). El sexenio de Televisa. Conjuras del poder mediático. México: Grijalbo.

VILLAMI, J. (2012). Peña Nieto el gran montaje. México: Grijalbo.

WIP México. Estudio 2012 de hábitos y percepciones de los mexicanos sobre Internet $y$ diversas tecnologías asociadas. Disponible en http://wip.mx 